\title{
Inflammatory Joint Disease of an Individual from St. Emmeram Cathedral, Nitra, Slovakia (14th - 18th Century AD)
}

Tonková M.

\author{
Constantine the Philosopher University in Nitra, Faculty of Natural Sciences, \\ Department of Zoology and Anthropology, Nábrežie mládeže 91, 949 74, Nitra, Slovakia. \\ tonkova.maria@gmail.com \\ Kolena B. \\ Constantine the Philosopher University in Nitra, Faculty of Natural Sciences, \\ Department of Zoology and Anthropology, Nábrežie mládeže 91, 949 74, Nitra, Slovakia.
}

\section{Vondráková M.}

Constantine the Philosopher University in Nitra, Faculty of Natural Sciences, Department of Zoology and Anthropology, Nábrežie mládeže 91, 949 74, Nitra, Slovakia.

\section{Luptáková L.}

Comenius University in Bratislava, Faculty of Natural Sciences, Department of Anthropology, Mlynská dolina B2, 842 15, Bratislava 4

Halaj M.

Jessenius - diagnostické centrum a.s., Špitálska 6, 949 50, Nitra, Slovakia

\section{Doi:10.5901/ajis.2013.v2n9p660}

\section{Abstract}

The paper presents pathological findings of one individual from the St. Emmeram Cathedral, where osteological remains were excavated during archaeological examination of the site Nitra - Castle hill, especially Nitra - Cathedral in 2008 and where bishops, canons and children (probably from aristocratic families) were buried since 14th till 18th century AD. The purpose of this study was determining pathological finding of skeletal remains of an individual from grave no. 235. Skeletal remains consist of right and left tibia, part of the left fibula (diaphysis with distal epiphysis) and foot bones, making ankylosis. Skeletal remains were anthropological analysed and sex of the individual was confirmed by aDNA analysis for increasing accuracy and reliability in sex determining. Presented osteological remains were anthropomorphological and paleopathological determined and diagnosed by RTG and CT scans to establish inflammatory disease of feet. After anthropological examination and widespread carefully study of osteo-archaeological and paleopathological literature we conclude on fact, that ankylosis was likely caused by rheumatoid arthritis $(R A)$.

Keywords: foot, tarso-metatarsal ankylosis, inflammatory disease, paleoanthropology, Post-Medieval Period, radio-diagnostic examination.

\section{Introduction}

\subsection{Rheumatoid Arthritis}

Rheumatoid arthritis (RA) is a chronic inflammatory disease, in which cells of the immune system attack healthy joints. RA is the most considered to be a systemic autoimmune-mediated disorder of all connective tissues (Horáčková, Strouhal and Vargová 2004). Etiology of RA is unknown, but there is acceptance of the hypothesis that it is the result of some environmental stimulus (probably an infectious organism of some type) acting on a genetic predisposition for the disease, which creates the pathological autoimmune response that destroys joint tissue (Fox 2001). The disease most 
frequently manifested in the fourth and fifth decades of life and continues through the life time of individual. Inflammatory process usually affects several joints and is usually symmetrical. In some cases, ankylosis may fuse carpals and tarsals into solid blocks (Ortner 2003). There is prevalence in incidence of disease at female population; RA affects $1 \%$ of men and $3 \%$ of women (Arnett et al. 1988).

\subsection{Archaeological context}

During the years 2008 - 2009, there was archaeological recovery research focused on the interior of the St. Emmeram Cathedral in Nitra (Figure 1). About 30 graves were excavated and dated to the Modern Period, $14^{\text {th }}-18^{\text {th }}$ century AD (Bednár and Poláková 2011).

For the purpose of this study we focused on individual from grave no. 235 (individual K 235), where foot ankylosis was observed. Because of unknown etiology of this paleopathological finding we tried to investigate the process of formation of this ankylosis with available methods and radio-diagnostic techniques.

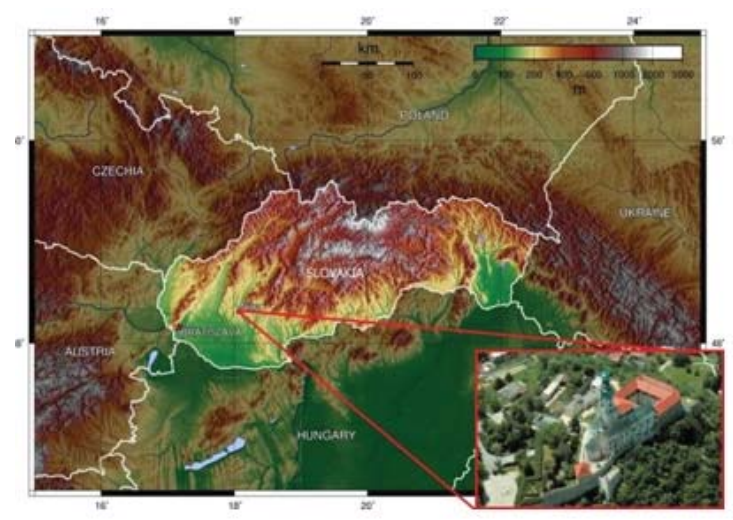

Figure 1: Nitra, Nitra - Castle in Slovakia, St. Emmeram Cathedral (basis of map http://upload.wikimedia.org/wikipedia /commons/thumb/a/aa/Slovakia_topo.jpg/800px-Slovakia_topo.jpg, photo of the Nitra - Castle http://www.mojacesta .wbl.sk/Nitra-a-jej-historia.html).

\section{Material and Methods}

Individual K 235 was detected during recovery research at probe $2 \mathrm{~B}$, situated at western side of the probe 2 . Orientation of grave was in West-East direction (the head to the West). Grave pit was clearly visible and observed at the depth 120 $\mathrm{cm}$ from the current floor of the church. It had been detected after reduction of the loose dusting powder of the $\mathrm{K} \mathrm{225}$, that violated from the western part and reduction of layer of K 229, which overlapped it. Based on the position of the lower extremities in situ, we could assume that skeletal individual was probably placed in a supine position, with extended arms and legs. State of preservation of remains was good, but grave was breached and by the research only the lower extremities, feet bones were successfully exhumed. Under the bones, as well as on the sides of the grave pit, was preserved wood from coffin. While exhuming skeletal remains, organic material was found under both lower legs, which is likely form of the lining of the coffin. In general, we can date grave to the $15^{\text {th }}$ up to half of the $16^{\text {th }}$ century AD.

The aim of this study was diagnosing of the pathological finding of the individual $\mathrm{K} 235$ by methods of Ortner (2003), Ortner and Putschar (1981) and Horáčková, Strouhal and Vargová (2004). Standard morphoscopic and morphometric methods by Knussmann (1988), Martin and Saller (1957), for the analysis of skeletal remains, were applied.

Individual age was estimated from maturation of skeleton based on epiphyseal closure (McKern and Stewart 1957, Buikstra and Ubelaker 1994). For sex determination were used methods of metric analysis by Olivier (1963), and Iscan and Miller-Shaivitz (1984) and aDNA analysis. aDNA analysis was instituted for increased accuracy and reliability in establishing the sex of this individual. Strict precautions were adhered to during each step of the sample preparation to eliminate risk of contamination by recent DNA (Pääbo, Higuchi and Wilson 2004). Extractions were performed three times and the sex determination results were verified for each extraction. The examined bone was initially exposed to UV light 
for 15 min on each side to de-activate possible modern contaminant DNA. Bone sample was taken from compact bone of the left tibia diaphysis. A minimum of $2 \mathrm{~mm}$ thick outer surfaces of the bone section was removed by scraping with sterile disposable scalpels, in accordance with Bouwman et al. (2006). The sample was then reduced to fine powder using liquid nitrogen. Powdered bone was washed twice in 0.5 M EDTA solution (pH 8.0) and in lysis buffer. Bone powder was resuspended in lysis buffer and $15 \mathrm{ml}$ proteinase $\mathrm{K}(20 \mathrm{mg} / \mathrm{ml})$ and incubated for $18 \mathrm{~h}$ at $56^{\circ} \mathrm{C}$. DNA was isolated by the SiMax ${ }^{\mathrm{TM}}$ Genomic DNA Extraction kit (Ecoli). To determine the sex, genetic markers on the sex-determination region $Y$ (SRY) on the $Y$ chromosome and the sequence on the macrosatellite DXZ4 on the $X$ chromosome were amplified, using nested PCR. The primer pairs used for genotyping gave $91 \mathrm{bp}(\mathrm{X})$ and $102 \mathrm{bp}(\mathrm{Y})$ products. The applied PCR assay and primers were designed by Luptakova et al. (2011) and Palmirotta et al. (1997).

Radiodiagnostical processing of material was realised by company Jessenius - Diagnostic Center, JSC in Nitra. The examination consisted of Anterior-Posterior projections made on a digital X-ray device DIGIGRAPH 9, and scanning of transversal sections at device Siemens Definition Flash 2x128 slice, followed by post-processing 3D assessment (by software TomoCon Lite). The method is based on the principle of collection and computer processing of large amount of data about value of the absorption of X-rays. They are obtained by a source of radiation - X-ray and its opposite detectors rotating around the object of interest. Subsequent computer processing is then able to assign in a given section to each point in the space corresponding absorption value and display it at grayscale on the monitor. This mathematical procedure is called tomographic reconstruction and its essence is the inverse Radon transformation. Pathological finding was investigated by the modern type of computed tomography by spiral (helical) method. It is a three-dimensional imaging method that collects data from a particular volume. Consequently, from these data, referred as "raw data", are reconstructed slices at the required levels.

\section{Results and Discussion}

\subsection{Osteological analysis of skeletal individual K 235}

Skeletal remains of the individual K 235 consist of the right and left tibia, part of the left fibula (diaphysis with distal epiphysis with postmortal fracture) and foot bones, showing pathological changes (see the Figure 2).

On the left side of the foot, we observe especially: calcaneus, talus, os naviculare, os cuneiforme mediale, os cuneiforme intermedium, os cuneiforme laterale, os cuboideum, ossa metatarsalia I, II, III, V. On the ride side of foot were observed: calcaneus, talus, os naviculare, os cuneiforme mediale, os cuneiforme laterale, os cuboideum, ossa metatarsalia I, III, phalanx proximalis digiti pedis I.

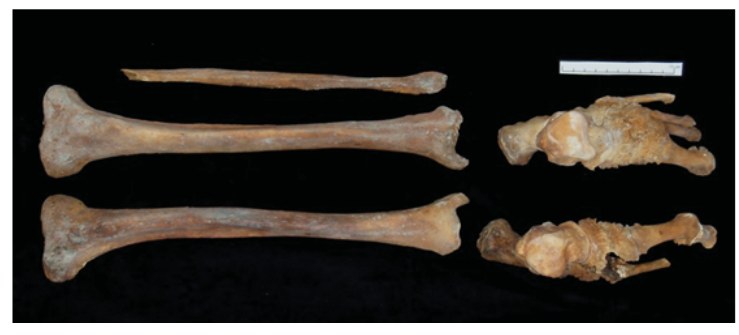

Figure 2: Human skeletal remains, individual K 235 (photo: Tonková, 2013).

Based on the macroscopic anthropological analysis, we could not certainly assume age and sex of the individual because of absenting or damaged the other skeletal remains (especially skull and pelvis). Age of the individual was estimated as adultus II and older. Metrical methods of sex determination by Olivier (1963), and Iscan and Miller-Shaivitz (1984) indicate on likely male sex. Consequently, we decided to increase accuracy and reliability in sex determining with aDNA analysis (genetic analysis). An individual is classified as male where both the DXZ4 and SRY products are detected. Therefore, based on both analyses, we could consider male sex of this individual.

According to the standard osteometrical analysis of the human skeletal remains of $K 235$, there were found metrical attributes. Particular values of measurements are given in the tables (Table 1, Table 2). 
Table 1. Metric characteristics of left and right tibia (K 235)

\begin{tabular}{|l|c|c|}
\hline \multicolumn{1}{|c|}{ Tibia } & dex & sin \\
\hline T1 - Total Length & 367 & 366 \\
\hline T1a - Maximum Length & 371 & 374 \\
\hline T1b - Medial Length & 364 & 465 \\
\hline T3 - Maximum Proximal Epiphyseal Breadth & 78 & 80 \\
\hline T6 - Maximum Distal Epiphyseal Breadth & 56 & 56 \\
\hline T8 - Maximum Midshaft A-P diameter & 29 & 29 \\
\hline T8a - A-P Diameter at the Nutrient Foramen position & 33 & 34 \\
\hline T9 - Midshaft transverse diameter & 25 & 23 \\
\hline T9a - Transverse Diameter at the Nutrient Foramen position & 26 & 26 \\
\hline T10 - Circumference of the Diaphysis & 86 & 86 \\
\hline T10b - Minimum Circumference of the Diaphysis & 74 & 77 \\
\hline
\end{tabular}

Table 2. Metric characteristics of left fibula (K 235)

\begin{tabular}{|l|c|}
\hline Fibula & $\sin$ \\
\hline Fi1 - Maximum Length & X \\
\hline Fi2 - Maximum Diameter at Midshaft & 16 \\
\hline Fi3 - Minimum Diameter at Midshaft & 13 \\
\hline Fi4 - Midshaft Circumference of the Diaphysis & 46 \\
\hline Fi4a - Minimum Circumference of the Diaphysis & 41 \\
\hline
\end{tabular}

\subsection{Description of pathological finding}

Skeletal remains of the individual K 235 consist of lower extremities. Because of absence other part of skeleton, pathological changes were observed only on both feet, with no signs of pathological process on the other parts of skeleton as tibia (dex. et. sin.) and fibula.

Based on macroscopic observation we could say that probably long-term inflammatory process caused significant pathological changes. We observed markedly damaged surface of feet bones. Inflammatory process probably destroyed the articular cartilage and it became completely destroyed, articular surfaces become irregular and deformed. Bone erosion was also observed on the contour of articular surfaces of joints.

Based on radiodiagnostical analysis of the individual $\mathrm{K} \mathrm{235}$, the marks of decalcination of skeleton, which is more pronounced periarticular / osteopenia / with erosive - destructive damage of, especially of the intertarsal articulation were observed in the CT image. Erosive destruction of articular facets of tarsal bones, with cortical usurations, subcortical geodes marked with sclerotic rim were also observed.

As most striking, an ankylosis of tarso-metatarsal segments (especially os naviculare, os cuneiforme mediale, os cuneiforme intermedium, os cuneiforme laterale, ossa metatarsalia I, II, III) of the left foot and ankylosis of the first metatarsal bone and phalanx proximalis of the great toe of the right foot (Figure 3) were detected as probably the terminal feature of the pathological changes. Based on analysis we could conclude that both of feet were occurred, and manifestation of inflammatory process was uniformly developed. Subchondral sclerosis of articulation facets of talus and calcaneus observed, and erosive changes in the posterior cortex of the calcaneal tuber of the left foot were also detected. Hallux valgus of the right foot was detected, with signs of erosive - destructive arthritis, periarticular calcifications and with ankylosis of I. metatarsophalangeal articulation of the right foot.

On the basis of literature (Figure 4) and radiological examination (Figure 5), we could say that in the articular areas of joints were also detected an osteolytic lesions like cysts, also called geodes. Based on comparison from other studies (Cruickshank, Macleod and Shearer (1954), Freund (1940) and Bywaters (1964)) we could say that those geodes are a well-recognized manifestation of rheumatoid arthritis. Most investigators have suggested that subchondral radiolucencies in rheumatoid disease result from inflammatory changes in the synovial lining of the articular cavity to creating pannus, which extends across the cartilaginous surface and eventually destroys cartilage and bone.

Even after radiodiagnostical examination and detailed macroscopic analysis we did not find any inflammatory lesions on the other part of the lower extremities (Figure 6). 


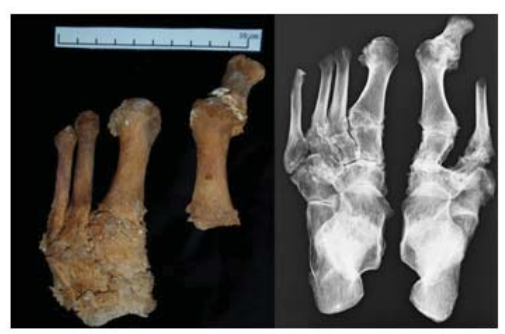

Figure 3: Ankyloses of the feet bones (left figure, photo: Tonková 2013), radiograph of the feet (right figure, author: Jessenius - diagnostic centre, JSC. 2013), anterior view of the individual K 235.

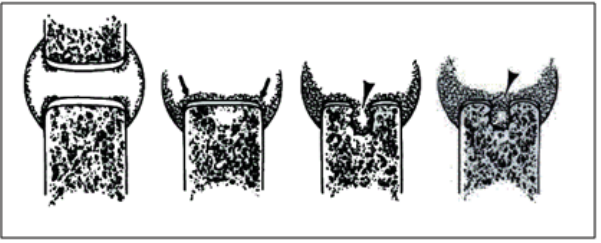

Figure 4: Pannus invading subchondral bone (arrows) resulting in trabecular erosion with formation of geodes (arrowheads) (Resnick, Niwayama and Coutts 1977).

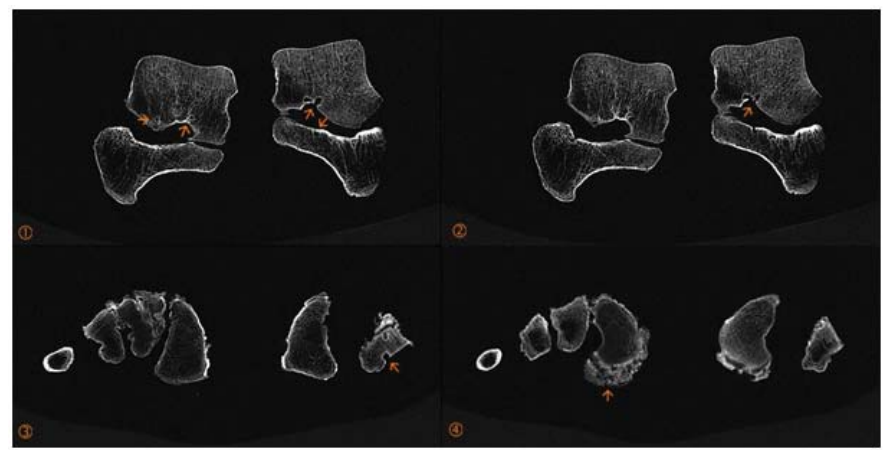

Figure 5: Subcortical geodes (orange arrow), individual K 235 (CT scan, author: Jessenius - diagnostic centre, JSC. 2013).

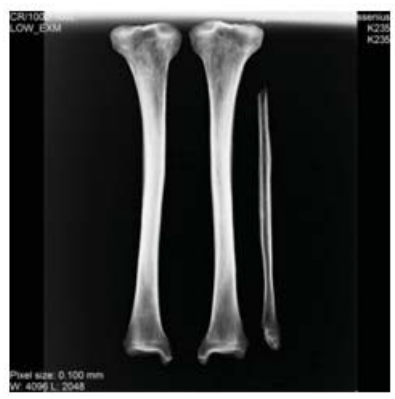

Figure 6: Lower extremities without signs of pathological process, anterior view of the individual K 235 (radiograph, author: Jessenius - diagnostic centre, JSC. 2013). 


\subsection{Differential diagnosis}

Because of taphonomical condition during decomposition, it is difficult to differentiate pathological conditions of joints in dry bone specimens. Therefore we decided to work out differential diagnosis to explain the etiology of pathological finding of the individual K 235.

Following potential diseases were taken under consideration:

A) At first, we hypothesized on spondyloarthropathy. Spondyloarthropathy (SpA) includes Ankylosing spondylitis, reactive arthritis, psoriatic arthritis, arthritis related to inflammatory bowel diseases, as well as undifferentiated SpA (Kim, Uhm and Inman 2005). Skeletal involvement in diseases of spondyloarthropaties group tends to be asymmetric and predominantly affects sacroiliac joints and spine, lower extremities are less commonly affected. The most commonly affected joints in ankylosing spondylitis are the sacroiliac joints, the joints of the spine, and the costo-vertebral joints. In the appendicular skeleton the most common parts are hips and shoulders (Van der Linden and Van der Heijde 2001). Ankylosing spondylitis prevailingly involves males and reactive bone formation and ankylosis is common feature (Ortner 2003).

In case of psoriatic arthritis, as a seronegative spondyloarthropathy associated with the chronic autoimmune skin disease psoriasis (Benett 2000), equally it is observed affection at male and female. It is more commonly polyarticular disease. The joints manifestations include erosive destruction, which may be very similar to rheumatoid arthritis or ankylosing spondylitis (Helliwell and Wright 1998). Benett (2000) report that bone density in psoriatic arthritis remains is normal, unlike the osteoporosis associated with rheumatoid arthritis. Gladman and Rahman (2001) assume that psoriatic arthritis is probably the result of a genetic predisposition of the disease in which an infectious agent (streptococcal organism) leads to an atypical immune response.

We would like to draw attention to the fact that individual K 235 consists of the lower extremities, and other parts of the skeleton are absenting. Therefore we could not describe, observe pathological changes like ankylosing spondylitis and psoriatic arthritis on the other parts of the skeleton. Second fact is that observed pathological changes of the individual $\mathrm{K} 235$ were notices symmetrical on both feet.

B) In the second group of diseases, that may affect joints of the feet are erosive arthropathies as a gout (arthritis uratica) and neuropathic osteoarthropaty - Charcot foot. The most common causes of Charcot joint are tabes dorsalis, a late manifestation of neurosyphilis, syringomyelia, diabetic neuropathy and traumatic nerve damage. As a result of disease could be severe destruction, attrition, and fragmentation of the joint ends of the bones, osteoporosis or osteosclerosis and transmetatarsal pathological fracture. Severe eburnation and articular grooving, as well as reactive exostoses of superimposed degenerative arthritis should be observed. The involved joint could be knee, hip, shoulder, ankle, tarsus and elbow (Ortner 2003). In case of gout, there is a strong sex predilection that 9 of 10 patients are males. Gouty arthritis affects mostly joints of the extremities and the most common location is the metatarsophalangeal joint of the great toe (Ortner and Putschar 1981). In the worst stage of the disease at the periphery of the joint gouty tophi - clusters of urate are presented, that in the tissue act as a foreign body and cause focal osteolysis with necrosis. Osteolytic lesions of sclerotic rim are created around (Horáčková, Strouhal and Vargová 2004).

In comparison with our skeletal individual K 235, eburnation or scooped-out defects were not observed.

C) As the most probable diagnosis for our finding is foot alteration affected by rheumatoid arthritis. RA usually involves multiple joints and is frequently symmetrical. The most common resulted from inflammatory process which affected hands, feet, wrists and elbows (Roberts and Manchester 1995). The disease process starts with inflammatory infiltration and proliferation of the synovium, and destroys and disfigures the joint. Untreated cases ended with loosening of the joint with subluxation or ankylosis. Carpometacarpal and tarsometatarsal joints may also be found ankylosed. Usually in flexed position are observed ankylosis of the large joints and interphalangeal joints. Ortner and Putschar (1981) claim that excessive bone resorption, probably on a basis of neurovascular disturbance, is occasionally observed. It occurs most frequently on hands or feet, resulting in concentric atrophy of metacarpals, metatarsals, and phalanges.

We compared our pathological finding with other findings described in available literature. We chose examples of very similar or even equal cases of probable RA from studies of Boston et al. (2009) and Ortner and Putschar (1981). Boston et al. (2009) detected lesions consistent with rheumatoid arthritis on feet of one ageing female (no. 5041, St George's Church, Bloomsbury, England). The tarsals of the left foot had fused and the right hand was also affected by inflammatory process. Ortner and Putschar (1981) describe another possible case of RA at the skeletal remains of the individual excavated in Cathedral Green and Winchester, England (MNNH XXIII, Burial 2.) Probably, there was a bilateral 
ankylosis of most tarsometatarsal joints accompanied by marked osteoporosis. The interphalangeal joint of the right great toe was fused as well. One more case of possible RA was described in work by Horáčková, Strouhal and Vargová (2004). Ankylosis of feet joints caused probably by inflammatory process was observed at adult individual from St. Peter and Pavol temple, Brno, Czech Republic.

\section{Conclusion}

Based on anthropological examination, radiological examination and widespread carefully study of osteo-archaeological and paleopathological literature we conclude, that ankylosis was most likely caused by rheumatoid arthritis (RA). There exists one more possibility- whether inflammatory changes could not be caused by the CRA - chronic reactive arthritis. For increasing accuracy of our results and resolve this possibility it might be appropriate to take another molecular or genetic analysis to confirm the etiology of pathological finding.

Our results point to the fact that RA was also presented at the historic populations and not just presented as a disease of current human population.

\section{Acknowledgement}

This work was supported by VEGA Grant No. 2/0034/11 - "Characteristic properties of components of the material culture from medieval settlements and burial places" and grant No. VII/51/2013 - "Anthropological expertise of the skeletal remains of individuals from the locality Nitra - Castle Hill, with a focus on exploration and assessment of the paleopathological findings".

\section{References}

Arnett, F. C., Edworthy, S. M., Bloch, D. A., Mcshane, D. J., Fries, J. F., Cooper, N. S., Healey, L. A., Kaplan, S. R., Liang, M. H., Luthra, H. S., Medsger Jr., T. A., Mitchell, D. M., Neustadt, D. H., Pinals, R. S., Schaller, J. G., Sharp, J. T., Wilder, R. L., \& Hunder, G. G. (1988). The American Rheumatism Association 1987 revised criteria for classification of rheumatoid arthritis. Arthritis and Rheumatism, 31(3), 315-24.

Bednár, P., \& Poláková, Z. 2011. Archeologický výskum Katedrály sv. Emeráma. AVANS, 37-40.

Benett, R. M. (2000). Psoriatic Arthritis. in W Koopman (ed.): Arthritis and Allied Conditions, 14th. Philadelphia: Lippincott Williams and Wilkins, 1345-1361.

Boston, C., Boyle A., Gill, J., \& Witkin, A. (2009). In the vaulth beneath, Archaeological recording at St. Georges's Church, Bloomsbeury. Oxford Arcgaeology, 234, ISBN 978-0-904220-53-7.

Bouwman, S.A., Chilvers, R.E., Brown, A.K., \& Brown, A.T. (2006). Brief communication: identification of the authentic ancient DNA sequence in a human bone contaminated with modern DNA. American Journal of Physical Anthropology , 131(3), 428-431.

Buikstra, J. E., \& Ubelaker, D. H. (1994). Standards for Data Collection from Human Skeletal Remains. Fayetteville, AR: Arkansas Archeological Survey Research Series 44.

Bywaters E. G. L. (1964). The hand in Radiological Aspects of Rheumatoid Arthritis. Amsterdam, Excerpta Medica International Congress series 61,43 .

Cruickshank, B., Macleod, I. G., \& Shearer, W. S. (1954). Subarticular pseudocysts in rheumatoid arthritis. Journal of the Faculty of Radiologists, 5(3), 218-226.

Fox, D. (2001). Etiology and pathogenesis of rheumatoid arthritis. In W Koopman (ed.): Arthritis and Allied Conditions, 14th. Philadelphia: Lippincott Williams and Wilkins, 1085-1102.

Freund, E. (1940). The pathological significance of intra-articular pressure. Medical Journal, 47, 192-203.

Gladman, D., \& Rahman, P. (2001). Psoriatic arthritis. In S Ruddy, E HarrisJr., and C Sledge (eds.): Kelley's Textbook of Rheumatology, 6th. Philadelphia: Saunders, 1071-1079.

Helliwell, P., \& Wright, V. (1998). Spondyloarthropathies. Psoriatic arthritis: Clinical features. In J Klippel and P Dieppe (eds.): Rheumatology, 2nd. London: Mosby, $22.1-22.8$.

Horáčková, L., Strouhal, E., \& Vargová, L. (2004). Panoráma biologické a sociokultúrní antropologie 15. Základy paleopatologie. NAUMA, Brno, 263.

Iscan, M. Y., \& Miller-Shaivitz, P. (1984). Discriminant Function Sexing of the Tibia. Journal of forensic sciences, 29(4),1087 - 1093.

Kim, T.-H., Uhm, W.-S., \& Inman, R. D. (2005). Pathogenesis of ankylosing spondylitis and reactive arthritis. Current Opinion in Rheumatology, 17, 400-405.

Knussmann, R. (1988). Anthropologie. Band I. Wesen und Methoden der Anthropologie. Gustav Fischer Verlag, Stuttgart, 743.

Luptakova, L., Babelova, A., Omelka, R., Kolena, B., Vondrakova, M., \& Bauerova, M. (2011). Sex determination of early medieval individuals through nested PCR using a new primer set in the SRY gene. Forensic science international, 207, 1-5. 
Martin, R., \& Saller, K. (1957). Lehrbuch der Anthropologie. In systematischer Darstellung mit besonderer Berücksichtigung der anthropologischen Methoden. Band 1. Gustav Fischer Verlag , Stuttgart, 661.

Mckern, T. W., \& Stewart, T. D. (1957). Skeletal Age Changes in Young American Males. Quartermaster Research and Development Center, US Army, Technical Report EP - 45, Natick.

Olivier, G. (1963). Pratique anthropologique. 292 pp. Preface by proof. H. V. Vallois. 1960. Vigot Fréres. 40 NF American Journal of Physical Anthropology, 21 (2), 238.

Ortner, D. J., \& Putschar, W.G. (1981). Identification of Pathological Conditions in Human Skeletal Remains. Smithsonian Contributions to Anthropology, Smithsonian Institution Press. Washington, D. C., 28, 479.

Ortner, D. J. (2003). Identification of pathological conditions in human skeletal remains. 2nd ed. Academic press. Washington USA, 645.

Palmirotta, P., Verginelli, F., Di Tota, G., Battista, P., Cama, A., Caramiello, S., Capasso,L., \& Mariani-Constantini, R. (1997). Use of a multiplex polymerase chain reaction assay in the sex typing of DNA extracted from archaeological bone. International Journal of Osteoarchaeology, 7(6), 605-609.

Pääbo, S., Higuchi, G. R., \& Wilson, C. A. (1989). Ancient DNA and the polymerase chain reaction. Journal of Biological Chemistry, 264, 9709-9712.

Resnick, D., Niwayama, G., \& Coutts, R. D. (1977). Subchondral Cysts (Geodes) in Arthritic Disorders: Pathologic and Radiographic Appearance of the Hip Joint. American Journal of Roentgenology, 128, 799-806.

Roberts, C., \& Manchester, K. (1995). The archaeology of disease. 2nd edition, New York.

Van der Linden, S., \& Van der Heijde, D. (2001). Spondyloarthropathies. Ankylosing spondylitis. In S Ruddy, E Harris Jr., and C Sledge (eds.): Kelley's Textbook of Rheumatology, 6th. Philadelphia: Saunders, 1039-1053.

\section{References Online}

Figure 1: basis of map online available: http://upload.wikimedia.org/wikipedia/commons/thumb/a/aa/Slovakia_topo.jpg/800pxSlovakia topo.jpg , (accessed June 2013).

Photo of the Nitra - Castle online available: http://www.mojacesta.wbl.sk/Nitra-a-jej-historia.html, (accessed June 2013). 